\title{
Aplikasi Kalkulator Fisika untuk Sekolah Menengah Tingkat Pertama (SMP) Berbasis Adobe Flash Pro CS6 Sebagai Pengembangan Media Pembelajaran
}

\author{
Alhidayatuddiniyah T.W. ${ }^{1}$ \\ Program Studi Informatika. Fakultas Teknik, Matematika dan IPA. \\ Universitas Indraprasta PGRI, Jalan Nangka No. 58 C, Tanjung Barat, DKI Jakarta. \\ Email : alhida.dini@gmail.com
}

\begin{abstract}
The purpose of this research is to: (1) produce application of Physics Calculator for Junior High School (SMP) based on Adobe Flash Pro CS6 and (2) to know the feasibility of Physics Calculator application. This application presents a model of physics formula based on basic competence with animation on each material and practice questions with the model referring to UNCBT standard (National Test-Computer Based Test), in addition to the completion of output in Physics Calculator application showing how to solve. The research and development method used refers to the concept of ADDIE. The feasibility test of Physics Calculator application is done by distributing assessment sheet or validation to two media experts, two material experts, and $9^{\text {th }}$ grade student SMPN 102 Jakarta responses. The percentage of respondents' assessment of Physics Calculator app by media experts, material experts, and students is $93.45 \%, 94.10 \%$, and $92.44 \%$. From the tests performed known menu and application features in accordance with the design and work well on Windows 10 operating system, and learning media becomes more interesting and innovative.
\end{abstract}

Keywords: calculator, Adobe Flash Pro CS6, validation, operating system Windows 10, learning media.

Abstrak: Tujuan penelitian ini untuk: (1) menghasilkan aplikasi Kalkulator Fisika untuk Sekolah Menengah Tingkat Pertama (SMP) berbasis Adobe Flash Pro CS6 dan (2) mengetahui kelayakan aplikasi Kalkulator Fisika. Aplikasi ini menyajikan model perhitungan rumus fisika yang berdasarkan kompetensi dasar dengan animasi pada setiap materi dan soal-soal latihan dengan model yang mengacu pada standar UN-CBT (Ujian Nasional-Computer Based Test), selain itu output penyelesaian pada aplikasi Kalkulator Fisika menampilkan cara penyelesaiaanya. Metode penelitian dan pengembangan yang digunakan mengacu pada konsep ADDIE. Pengujian kelayakan aplikasi Kalkulator Fisika dilakukan dengan membagikan lembar penilaian atau validasi kepada dua ahli media, dua ahli materi, dan respon siswa kelas IX SMPN 102 Jakarta. Hasil persentase penilaian responden terhadap aplikasi Kalkulator Fisika oleh ahli media, ahli materi, dan siswa sebanyak $93.45 \%, 94.10 \%$, dan $92.44 \%$. Dari pengujian yang dilakukan diketahui menu dan fitur aplikasi sesuai dengan rancangan dan berfungsi dengan baik pada operating system Windows 10, serta media pembelajaran menjadi lebih menarik dan inovaif.

Kata kunci: kalkulator, Adobe Flash Pro CS6, validasi, operating system Windows 10, media pembelajaran.

\section{PENDAHULUAN}

Perkembangan ilmu pengetahuan dan teknologi yang sangat pesat saat ini menyebabkan hampir semua aktivitas manusia dapat dikendalikan oleh aplikasi Ilmu Pengetahuan dan Teknologi (IPTEK). Dengan semakin berkembangnya ilmu pengetahuan dan teknologi, maka diperlukan suatu usaha yang dapat mempermudah mengetahui ilmu-ilmu tersebut.

Media yang berbasis IT dengan waktu yang relatif singkat dan dengan fasilitas minim akan memberikan hasil yang maksimal dalam proses transfer of knowledge, dengan artian bahwa 
informasi yang bersifat audio, visual, maupun audio visual yang selanjutnya akan mempengaruhi pada kecerdasan kognitif, psikomotor, maupun afektif pada diri siswa.

Keterkaitan ilmu fisika dengan kehidupan sehari-hari seharusnya menjadikan fisika sebuah ilmu yang menarik untuk dipelajari. Pembelajaran fisika selama ini dianggap kurang menarik karena hanya menekankan pada rumus-rumus matematik tanpa digali dari konsep dasar terlebih dahulu. Oleh karena itu, perlu dibuat media pembelajaran yang dapat memudahkan siswa dalam memecahkan masalah-masalah fisika yang sebelumnya rumit untuk dipelajari menjadi lebih sederhana.

Komunikasi adalah salah satu hal vital dalam pendidikan. Seorang pendidik yang dapat berkomunikasi kepada siswa secara efektif, maka transfer ilmu dan nilainya pun dapat berjalan efektif dan optimal. Jika transfer ilmu dan nilai tidak berjalan efektif, maka akan berdampak pada siswa yang akan lambat dalam memahami pelajaran. Dan lebih bahaya, jika siswa salah menginterpretasikan maksud dari pendidik, sehingga yang siswa pahami justru sesuatu yang salah.

Pada kegiatan belajar mengajar (KBM) diperlukan experimental learning. Namun, ada kalanya pada KBM dihadapkan pada materi yang tidak dapat dilakukan eksperimennya. Selain itu, kurangnya fasilitas laboratorium membuat diperlukannya alat bantu pengajaran, yaitu berupa pembelajaran menggunakan animasi interaktif.

Salah satu media pembelajaran yang banyak digunakan saat ini adalah media pembelajaran dengan menggunakan komputer. Salah satu program yang banyak digunakan dalam membuat media pembelajaran yang berisi animasi, grafik, teks, dan suara adalah Adobe Flash. Dan media pembelajaran yang digunakan dalam penelitian ini, yaitu Adobe Flash Professional CS6.

\section{KAJIAN PUSTAKA}

a. Materi Fisika SMP

Materi fisika yang diajarkan pada sekolah menengah tingkat pertama meliputi besaran dan pengukuran, kinematika, gaya dan hukum Newton, tekanan, energi, usaha, getaran, gelombang, cahaya, alat-alat optik, listrik, energi dan daya listrik, kemagnetan, induksi elektromagnetik, dan tata surya. Beberapa materi yang akan diterangkan berikut ini, yaitu Kinematika dan Induksi Elektromagnetik.

\section{Kinematika}

Benda dikatakan bergerak jika kedudukannya senantiasa berubah terhadap suatu acuan tertentu. Dalam hal ini, kinematika adalah ilmu yang memelajari tentang gerak tanpa memerhatikan penyebab timbulnya gerak.

a. Gerak Lurus Beraturan

Gerak lurus beraturan adalah gerak suatu benda pada lintasan lurus dengan kecepatann konstan. Secara matematis dinyatakan dengan:

$$
v=\frac{\Delta x}{\Delta t}
$$

b. Gerak Lurus Berubah Beraturan

Gerak lurus berubah beraturan adalah gerak suatu benda pada lintasan garis lurus yang percepatannya tetap. Percepatan tetap menunjukkan bahwa besar dan arahnya sama.

Persamaan-persamaan pada GLBB, yaitu: 
GLBB yang dipercepat

$$
\begin{gathered}
v_{t}=v_{0}+a \cdot t \\
s=v_{0} \cdot t+\frac{1}{2} \cdot a \cdot t^{2} \\
v_{t}^{2}=v_{0}^{2}+2 \cdot a \cdot s
\end{gathered}
$$

GLBB yang diperlambat

$$
\begin{gathered}
v_{t}=v_{0}-a \cdot t \\
s=v_{0} \cdot t-\frac{1}{2} \cdot a \cdot t^{2} \\
v_{t}^{2}=v_{0}^{2}-2 \cdot a \cdot s
\end{gathered}
$$

2. Induksi Elektomagnetik

Arus induksi adalah arus yang timbul karena perubahan garis gaya magnet yang memotong kumparan. (Miftah M. Muslim, 2008: 43)

Gaya gerak listrik induksi (GGL Induksi) merupakan tegangan (beda potensial) yang terjadi karena perubahan garis gaya magnet yang memotong kumparan.
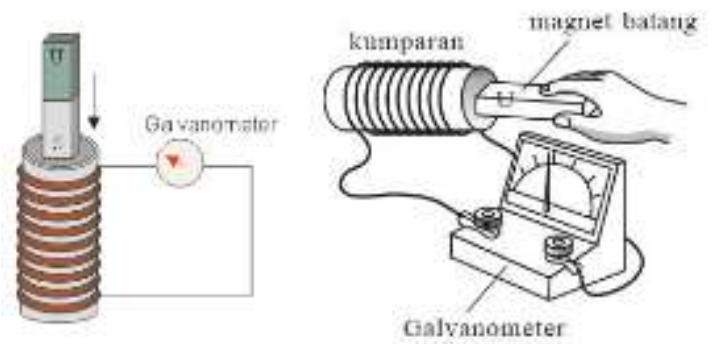

Gambar 1. Gaya gerak listrik induksi (sumber: google.com)

Ada tiga faktor yang mempengaruhi GGL Induksi, yaitu: kecepatan gerakan magnet atau kecepatan perubahan jumlah garis-garis gaya magnet (fluks magnetik), jumlah lilitan, dan medan magnet.

Pada induksi elektromagnetik terjadi perubahan bentuk energi gerak menjadi energi listrik. Induksi elektromagnetik digunakan pada pembangkit energi listrik

a. Generator

Generator dibedakan menjadi dua, yaitu generator arus searah (DC) dan generator arus bolak-balik (AC). Prinsip kerja generator, yaitu mengubah energi gerak menjadi energi listrik.

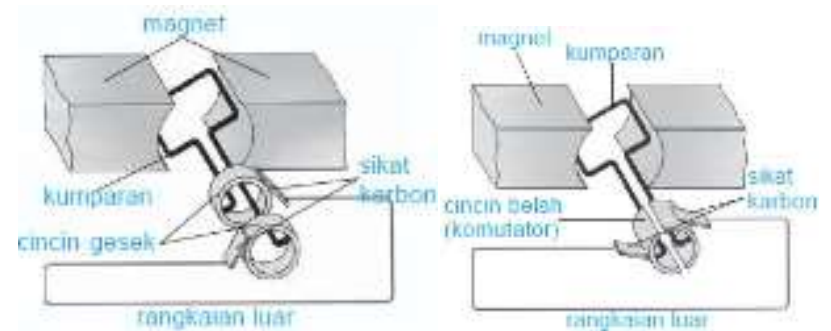

Gambar 2. Prinsip kerja generator (sumber: google.com)

b. Transformator

Transformator merupakan alat yang dipakai untuk menaikkan (trafo step up) dan menurunkan (trafo step down) tegangan listrik bolak-balik. (Diyan Parwatiningtyas, dkk, 2016: 168). 


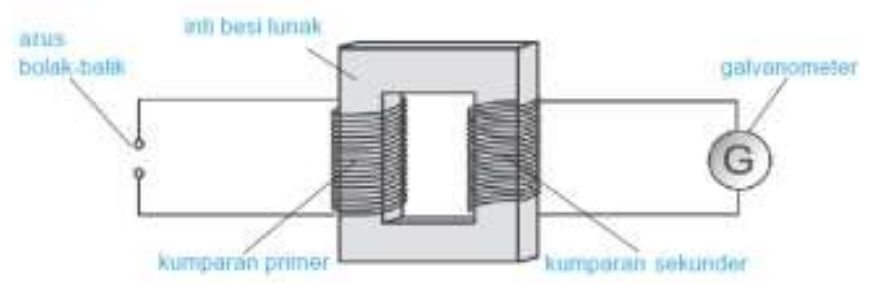

Gambar 3. komponen utama transformator (sumber: google.com)

Persamaan untuk transformator, yaitu:

$$
\begin{gathered}
P_{s}=P_{p} \\
V_{s} \times I_{s}=V_{p} \times I_{p} \\
V_{s}: V_{p}=I_{p}: I_{s} \\
V_{s}: V_{p}=N_{s}: N_{p} \\
N_{s}: N_{p}=I_{p}: I_{s}
\end{gathered}
$$

dengan: Ps = daya sekunder (watt)

$\mathrm{Pp}=$ daya primer (watt)

$\mathrm{Vs}=$ tegangan sekunder (volt)

$\mathrm{Vp}=$ tegangan primer (volt)

Is $=$ kuat arus sekunder (ampere)

Ip = kuat arus primer (ampere)

Ns = jumlah lilitan kumparan sekunder

$\mathrm{Np}=$ jumlah lilitan kumparan primer

Efisiensi transformator adalah besaran yang menyatakan perbandingan antara daya keluaran $\left(\mathrm{P}_{\text {out }}\right)$ dengan daya masukan $\left(\mathrm{P}_{\text {in }}\right)$. Nilai efisiensi transformator dirumuskan sebagai: (Ahmad Zaelani, 2006: 479)

$$
\eta=\frac{P s}{P p} \times 100 \%
$$

dengan: $\eta^{=}$efisiensi transformator $(\%)$

\section{b. Animasi Adobe Flash Pro CS6}

Flash adalah program animasi berbasis vektor yang bisa menghasilkan file kecil (ringan) sehingga mudah diakses pada halaman web tanpa membutuhkan waktu loading yang lama. Flash menghasilkan file dengan ekstensi .FLA. Setelah file tersebut siap untuk dimuat ke halaman web, selanjutnya file akan disimpan dalam format .SWF agar dapat dibuka tanpa menginstall perangkat lunak Flash, tetapi cukup menggunakan Flash Player yang dipasang pada browser berbasis Windows. (Dhani Yudhiantoro, 2006: 1-2)

Agar orang lain yang berbeda komputer dapat melihat animasi yang telah dibuat, harus dibuat file yang berekstension .exe atau html untuk komputer yang berbasis Windows. Dan .app untuk komputer yang berbasis Macintosh. (Hidayatullah, 2011: 34)

Adobe Flash merupakan gabungan konsep pembelajaran dengan teknologi visual yang mampu menghasilkan fitur-fitur baru yang dapat dimanfaatkan dalam pendidikan. Pembelajaran berbasis multimedia diharapkan dapat memudahkan penyampaian materi serta dapat menyajikan materi pelajaran yang lebih menarik dan tidak monoton. Siswa dapat mempelajari materi pelajaran tertentu secara mandiri dengan komputer yang dilengkapi program multimedia. 
Program Adobe Flash terdiri dari beberapa versi, dalam hal pengembangan media pembelajaran ini, versi yang digunakan adalah Adobe Flash Pro CS6.

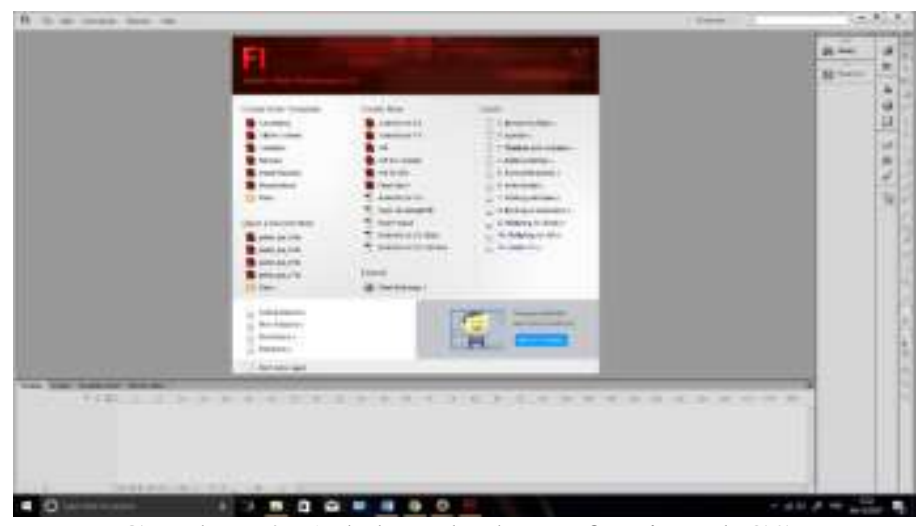

Gambar 4. Adobe Flash Professional CS6

\section{METODE PENELITIAN}

Penelitian aplikasi kalkulator fisika sebagai pengembangan media pembelajaran berbasis Adobe Flash Pro CS6 yang kompatibel pada sistem operasi Windows 10 diujicobakan pada siswa kelas IX SMPN 102 Jakarta.

a. Data Penelitian

Data yang digunakan dalam penelitian ini meliputi:

1. Rumus-rumus fisika untuk Sekolah Menengah Tingkat Pertama (SMP), dimana pengumpulan data rumus-rumus fisika dilakukan dengan studi pustaka.

2. Data kondisi belajar mengajar pendidik dan siswa. Data ini diperoleh dengan melakukan wawancara melalui tatap muka dan tanya jawab langsung antara peneliti terhadap pendidik yang memberikan materi fisika.

3. Hasil validasi oleh ahli media dan ahli materi untuk perbaikan produk. Produk yang telah diperbaiki diujikan ke siswa.

4. Hasil angket dari uji produk pada siswa untuk perbaikan sistem.

b. Alir Penelitian

Adapun alir penelitian ini, yaitu:

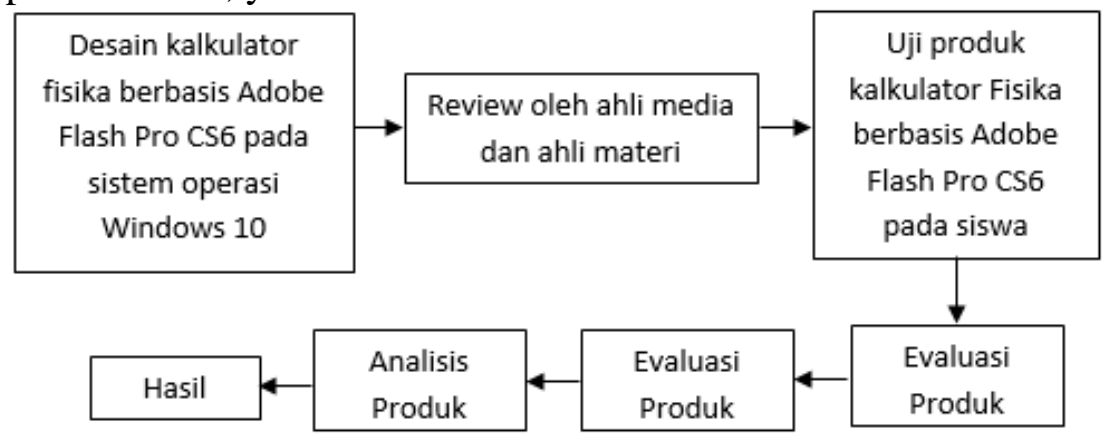

Gambar 5. Alir penelitian aplikasi kalkulator fisika

c. Tahapan Penelitian

Tahapan pelaksanaan penelitian rancang bangun aplikasi kalkulator fisika pada sistem operasi Windows 10 berbasis animasi Adobe Flash Pro CS6, yaitu: 
1. Tahapan perencanaan

Tahapan perencanaan penelitian ini meliputi perencanaan jadwal kegiatan, pengumpulan materi yang akan digunakan, dan kebutuhan sistem penelitian.

2. Tahapan Analisis

Tahapan analisis berupa kegiatan pendahuluan yang dilakukan sebelum menentukan konsep pembuatan aplikasi kalkulator fisika dengan Adobe Flash Pro CS6, yang terdiri dari pemodelan data dan proses, dengan mengidentifikasi tujuan media pembelajaran dan mengidentifikasi karakteristik siswa.

3. Tahapan Perancangan

Pada tahapan perancangan dibuat desain software kalkulator dan desain media pembelajaran. Perancangan desain ini menggunakan program Adobe Flash Pro CS6, yaitu:

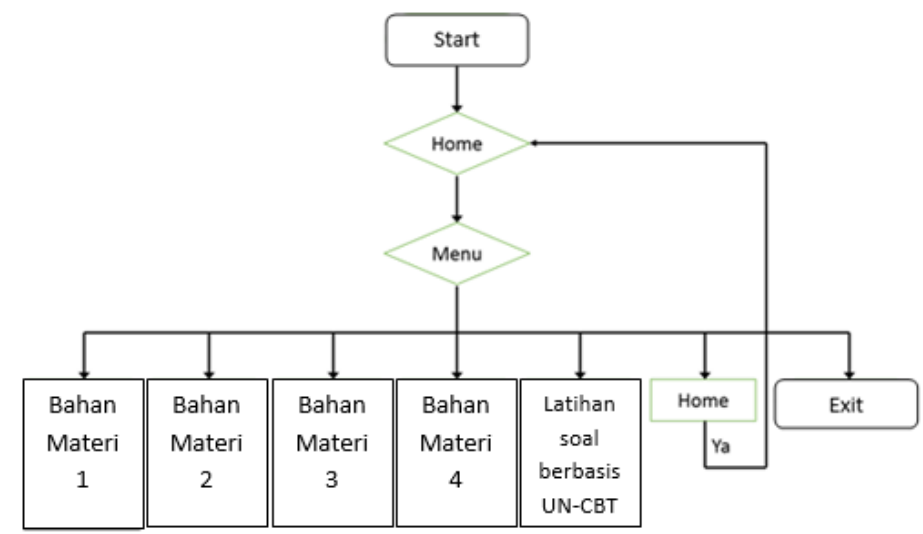

Gambar 6. Bagan desain aplikasi kalkulator fisika berbasis Adobe Flash Pro CS6

4. Tahapan Produksi

Pada tahapan produksi dihasilkan produk awal yang selanjutnya akan berlanjut dengan review oleh ahli materi dan ahli media pembelajaran. Tahapan produk yang disusun meliputi:

a. Pembuatan desain bahan-bahan kalkulator fisika menjadi produk multimedia berupa desain materi pembelajaran, pemilihan gambar dan menyusunnya sesuai dengan lay-out, menentukan tampilan, dan menyusun program evaluasi.

b. Pengeditan materi kalkulator fisika untuk meneliti desai-desain yang kurang sesuai, baik dari sisi kemudahan penggunaannya, bacaannya, ataupun pengetikannya.

5. Tahapan Pengujian dan Evaluasi

Hasil produksi yang telah di review akan direvisi dan produk diuji cobakan kepada siswa. Siswa diberikan angket mengenai produk yang divalidasi oleh ahli materi dan ahli media, kemudian dianalisis dan saran-sarannya dijadikan dasar merevisi produk. Adapun analisis data angket yang diberikan pada siswa berupa empat kategori pernyataan, berdasarkan ADDIE, sebagai berikut:

Tabel 1. Kriterian Kelayakan Media Pembelajaran

\begin{tabular}{ccc}
\hline Kategori Pernyataan & Persentase & Kategori \\
\hline 1 & $80 \%-100 \%$ & Valid \\
2 & $60 \%-79,99 \%$ & Cukup valid \\
3 & $50 \%-59,99 \%$ & Kurang valid \\
4 & $0 \%-49,99 \%$ & Tidak valid (diganti) \\
\hline
\end{tabular}


Persentase dihitung berdasarkan:

$$
\text { Persentase }=\frac{\text { Skor yang diperoleh }}{\text { Skor maksimum }} \times 100 \%
$$

dengan: skor maksimum dan yang diperoleh dihitung berdasarkan setiap kriteria penilaian.

\section{HASIL PENELITIAN DAN PEMBAHASAN}

Produk yang dihasilkan dari penelitian ini berupa aplikasi kalkulator fisika sebagai media pembelajaran fisika berbasis animasi Flash Pro CS6 untuk kelas IX sebagai bahan belajar, evaluasi, dan latihan persiapan ujian nasional. Produk media pembelajaran ini dibuat dan dirancang oleh peneliti, dengan tujuan dapat digunakan sebagai alat bantu pendidik dalam menyampaikan materi dan juga sebagai sumber belajar mandiri yang sewaktu-waktu dapat digunakan oleh siswa di luar sekolah.

Pengembangan media pembelajaran ini menggunakan model perancangan media pembelajaran model ADDIE, dengan 5 tahapan antara lain Analysis, Design, Development, Implementation, dan Evaluation.

Adapun tahap-tahap penelitian pengembangan yang telah peneliti lakukan meliputi:

a. Analysis, tahap analisis terhadap pengembangan produk yang dilakukan terdiri dari analisis materi dan analisis media pembelajaran. Dari analisis tersebut dihasilkan materi yang membutuhkan bantuan media sebagai alat bantu guru dalam menyampaikan materi sesuai dengan persyaratan yang memenuhi standar kompetensi. Dengan menggunakan aplikasi media pembelajaran animasi fisika berbasis Adobe Flash Pro CS6, guru dapat menyampaikan meteri yang tidak abstrak lagi dan dapat memberikan tugas tambahan untuk siswa. Selain itu, aplikasi ini diperlukan untuk menunjang kemampuan siswa dalam menyerap materi pelajaran.

b. Design, pada tahap ini dipaparkan tujuan pembelajaran, kegiatan belajar mengajar yang dilaksanakan akan menampilkan desain aplikasi media pembelajaran animasi berbasis Adobe Flash Pro CS6, dan latihan yang menampilkan animasi dan video yang sesuai dengan materi yang dapat diterapkan oleh guru serta siswa. Selain itu, pada tahap ini, dibuat lembar validasi oleh ahli media dan ahli materi.

c. Development, hasil dari tahap pengembangan yaitu prototipe berupa aplikasi kalkulator fisika sebagai media pembelajaran beranimasi berbasis Adobe Flash Pro CS6, aplikasi ini terdiri dari kompetensi dasar, kompetensi inti, materi ajar, animasi berupa gambar, video, dan latihan soal yang mengacu standar UN CBT.

d. Implementation, pada tahap ini pelaksanaan penelitian dan pengamatan yang diterapkan dengan diadakannya pelatihan aplikasi kalkulator fisika yang diterapkan di sekolah menengah tingkat pertama (SMP), disertakan pula lembar validasi uji coba produk yang diberikan kepada siswa.

e. Evaluation, hasil dari tahap implementasi diperoleh hasil kelayakan akan aplikasi kalkulator fisika yang diujicobakan dan telah divalidasi oleh ahli materi dan ahli media. 
Berikut ini, produk bahan ajar yang dibuat:
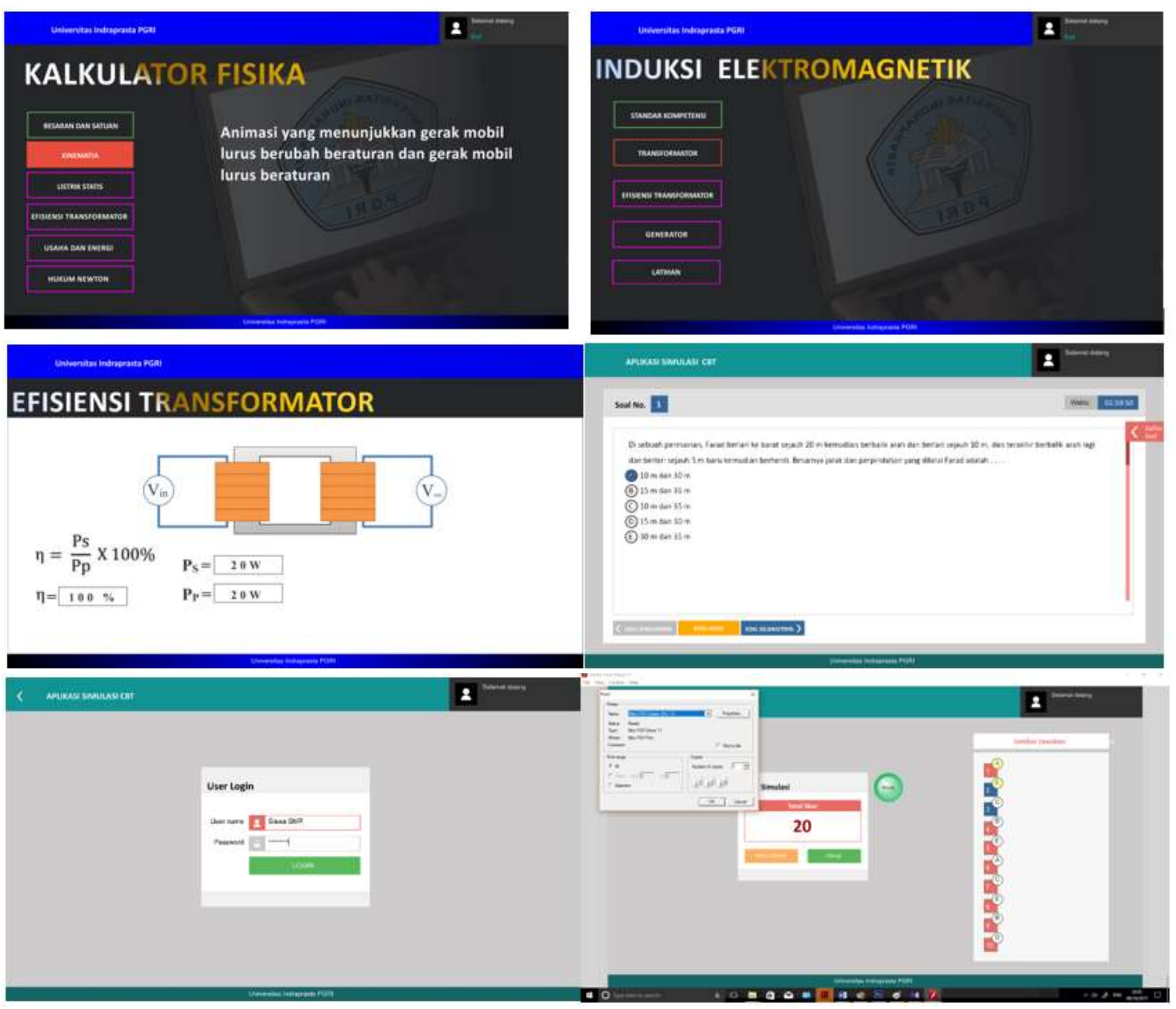

Gambar 7. Produk yang dibuat berupa materi, animasi, dan latihan soal berstandar UN CBT

Berdasarkan produk yang telah dibuat, berikut ini hasil validasi oleh ahli media, ahli materi, dan siswa:

a. Persentase hasil validasi oleh dua ahli media pada aplikasi kalkulator fisika sebagai pengembangan media pembelajaran berbasis Adobe Flash Pro CS6, yaitu $93.45 \%$. Penilaian validasi meliputi kesesuian desain slide, layout, penampilan isi, kejelasan gambar, kesesuaian animasi flash, ketepatan isi page, kesesuaian background dan warna, kecepatan pemrosesan perintah, ketepatan tombol perintah, dan mudah dalam penggunaannya. Saran dari validator pada aplikasi kalkulator fisika, yaitu menambahkan standar kompetensi materi pada aplikasi. Berikut hasil validasi oleh ahli media,

Tabel 2. Hasil validasi ahli media

\begin{tabular}{ccc}
\hline No & Aspek & Persentase \\
\hline 1 & Grafika & $92.86 \%$ \\
2 & Penggunaan & $93,75 \%$ \\
3 & Pengolahan Program & $93.75 \%$ \\
\hline
\end{tabular}


Rata-rata $\quad 93.45 \%$

b. Persentase hasil validasi oleh dua ahli materi yang pada aplikasi ini sebesar $94.10 \%$. Aspek yang dinilai oleh ahli materi adalah kebahasaan, aspek ilustrasi, kesesuaian animasi dengan materi yang ingin disampaikan, kesesuaian indikator dengan materi, dan soal evaluasi terhadap materi yang disampaikan. Berikut hasil validasi oleh ahli materi,

Tabel 3. Hasil validasi ahli materi

\begin{tabular}{ccc}
\hline No & Aspek & Persentase \\
\hline 1 & Ilustrasi & $100 \%$ \\
2 & Kebahasaan & $91.67 \%$ \\
3 & Kesesuaian Materi & $90.63 \%$ \\
\hline & Rata-rata & $94.10 \%$ \\
\hline
\end{tabular}

c. Persentase hasil validasi berupa angket oleh 20 siswa SMPN 102 Jakarta pada aplikasi ini sebesar $92.44 \%$. Berikut hasil validasi oleh siswa,

Tabel 4. Hasil validasi siswa

\begin{tabular}{ccc}
\hline No & Aspek & Persentase \\
\hline 1 & Ilustrasi & $92.08 \%$ \\
2 & Kebahasaan & $94.16 \%$ \\
3 & Kesesuaian Materi & $91.09 \%$ \\
\hline & Rata-rata & $92.44 \%$ \\
\hline
\end{tabular}

Rata-rata validasi dari ahli media, ahli materi, dan siswa diperoleh sebesar 93.33\% dengan kategori valid. Maka aplikasi kalkulator fisika sebagai pengembangan media pembelajaran berbasis Adobe Flash Pro CS6 layak digunakan oleh siswa dan guru dalam pembelajaran.

\section{KESIMPULAN}

Dari hasil penelitian yang telah dilakukan dapat ditarik kesimpulan bahwa, aplikasi kalkulator fisika sebagai media pembelajaran yang bersifat animasi berbasis Adobe Flash Professional CS6 untuk siswa kelas IX telah berhasil dibuat. Media ini termasuk dalam kategori baik sebagai media pembelajaran. Berdasarkan pengumpulan data validasi yang telah dilakukan oleh penilaian validator ahli media, ahli materi, dan siswa kelas IX, diperoleh persentase rata-rata sebesar $93.45 \%, 94.10 \%$, dan $92.44 \%$, dengan kategori valid, maka aplikasi kalkulator fisika sebagai media pembelajaran berbasis animasi Adobe Flash Pro CS6 pada Sekolah Menengah Tingkat Pertama sudah valid untuk digunakan dalam pembelajaran fisika dan dapat beroperasi dengan baik pada sistem operasi Windows 10 .

\section{SARAN}

Berdasarkan penelitian yang telah dilakukan, untuk selanjutnya perlu dibuatkan materi fisika yang lebih lengkap.

\section{DAFTAR PUSTAKA}

Hidayatullah, Priyanto, dkk. (2011). Animasi Pendidikan Menggunakan FLASH: Membuat Presentasi Visualisasi Materi Pelajaran Lebih Menarik. Bandung: Penerbit Informatika.

Muslim, Miftah, dkk. (2008). Cara Mudah Menghadapi Ujian Nasional 2008 IPA SMP. 
Jakarta: Grasindo.

Parwatiningtyas, Diyan, dkk. (2016). Fisika Universitas. Jakarta: Unindra Press.

Siswanto, dkk. (2013). Maestro Olimpiade Fisika SMP, Seri A. Jakarta: Penerbit Erlangga.

Sudjana N. \& Rivai A. (2005). Media Pengajaran. Bandung: Sinar Baru Algensindo.

Yuhiantoro, Dhani. (2006). Macromedia FLASH Professional 8. Yogyakarta: Penerbit ANDI Yogyakarta.

Zaelani, Ahmad, dkk. (2006). 1700 Bank Soal Bimbingan Pemantapan Fisika. Bandung: Yrama Widya. 